\title{
Construção e subjetividade na geração y no setor bancário: Um olhar sobre o Hong Kong Shangai Banking Corporation Bank Brasil S. A.
}

\author{
Ronaldo Edson Vieira da Silva \\ Centro Universitário de Brusque - Unifebe, Brasil \\ reevs86@yahoo.com.br \\ Claudemir Marcolla \\ Universidade do Vale do Itajaí, Brasil \\ claudemir.marcolla@hotmail.com \\ Everaldo da Silva \\ Universidade Federal de Santa Catarina, Brasil \\ prof.evesilva@gmail.com \\ Wellington Lima Amorim \\ Universidade Federal de Santa Catarina, Brasil \\ wellington.amorim@gmail.com
}

\section{Resumo}

A presente pesquisa, caracterizada como bibliográfica e qualitativa, teve, como objetivo geral, investigar como os gestores, no Banco Hong Kong Shangai Banking Corporation Bank Brasil S.A., desenvolvem habilidades e ferramentas para gerenciar as expectativas dos profissionais que pertencem à Geração Y. Como instrumentos de coleta de dados, utilizou-se um questionário com perguntas fechadas, respondido por 20 jovens dessa geração. Os resultados apontaram que os colaboradores da Geração Y possuem algumas características em sua personalidade que podem ser exploradas pela organização para aumentar a produtividade, respeitando o perfil profissional desses jovens. Identificou-se também, que os profissionais participantes deste estudo possuem algumas características que os tornam diferentes das demais gerações, no que diz respeito ao crescimento profissional, ao questionamento de tarefas, à necessidade de feedback rápido e reconhecimento profissional. Diante dos resultados obtidos, recomendou-se, à empresa participante da pesquisa, o uso, pelos gestores, de ferramentas de gestão, para que o capital humano esteja alinhado às perspectivas organizacionais da empresa e para que ocorra a minimização da rotatividade dos jovens Y.

Palavras-Chave: Geração Y; Gestão; Rotatividade.

Construction and Subjectivity in Generation Y in the Banking Sector: A Look at Hong Kong Shanghai Banking Corporation Bank Brazil S.A.

\section{Abstract}

The present research, characterized as bibliographical and qualitative, has as general objective to investigate how the managers of the Hong Kong Bank Shangai Banking Coporation Brazil Bank 
S.A. develop skills and tools to manage the expectations of professionals who belong to Generation Y. As instruments of data collection, a questionnaire with closed questions was used, answered by 20 youngs people of this generation. The results showed that the employees of Generation $\mathrm{Y}$ have some characteristics in their personality that can be exploited by the organization to increase productivity, respecting the professional profile of these young people. It was also identified that the professionals participating in this study have some characteristics that make them different from the other generations, regarding professional growth, questioning of tasks, the need for rapid feedback and professional recognition. In view of the obtained results, it was recommended to the company that participates in the research, the use of management tools by managers, so that human capital is aligned with the organizational perspectives of the company and to minimize the turnover of people Y.

\section{Introdução}

O sistema financeiro está constantemente se aperfeiçoando. Principalmente quando nos referimos ao capital humano. Nesse setor, atualmente, o ingresso de novos talentos com um perfil mais competitivo tem chamado a atenção. Os bancos possuem tecnologia, recursos financeiros e boa margem de lucros, sendo que a manutenção e a evolução dessa estrutura estão atreladas a um desenvolvimento sustentável do capital humano que pode ser utilizado nestas empresas. Nesse sentido, os profissionais que atuam nessas organizações, deveriam com $\mathrm{o}$ tempo, evoluem dentro da hierarquia, podendo assumir, a cada dois anos, novas funções. Entre esses profissionais, encontram-se tanto os da Geração X, composta pelas pessoas nascidas entre meados da década de 1960 e início dos anos de 1980 (LOMBARDIA, 2008); os Baby Boomers, que, são, de forma genérica, os que nasceram durante uma explosão populacional (SERRANO, 2010); e os da Geração Y, que compreende os nascidos nas décadas de 1980 e 1990 (LOMBARDIA, 2008).

Cabe mencionar que, que a evolução das práticas de gestão de pessoas, passando pela teoria científica, teoria clássica, burocracia e relações humanas, até o momento, diversas transformações ocorreram no mercado e que algumas dessas mudanças ocorreram em função das gerações que surgiram, cada qual com suas características particulares e seus fatores de motivação. Muitos dos gestores dessas organizações são Boomers ou da Geração
X, e grande parcela dos novos profissionais que formarão, nas próximas décadas, a força produtiva futura é da Geração Y. Em relação aos profissionais da Geração $\mathrm{Y}$, a boa gestão das instituições financeiras busca maximizar, ainda mais, as estruturas dos bancos e aumentar a margem de lucro. Para tanto, é fundamental que os bancos se preocupem em conhecer quem são esses profissionais, o que eles querem e como extrair o máximo de produtividade. E para isto é necessário desenvolver e aprimorar métodos de gestão que sejam eficazes.

Nesse contexto, os gestores dos bancos têm um papel relevante no que diz respeito à integração de forma eficaz dos jovens $Y$, pois esses jovens possuem um estímulo diferente do da geração Baby Boomers e da Geração X para uma carreira de sucesso. Considera-se que caiba ao banco e aos gestores identificar como fomentar os jovens $\mathrm{Y}$ e que, para que este fomento ocorra de forma eficaz o gerenciamento dessa geração deve ser pautado nas causas que diferem essa geração das demais. É preciso conhecer quem são esses jovens, o que querem e o que os motiva a alcançar seus objetivos. A pesquisa encontrase voltada ao setor bancário, em específico ao HSBC Bank Brasil S.A., e direciona-se a gestão da Geração $Y$, a qual tem muito que contribuir com o mercado sem ir contra os princípios que formam seu caráter. Isso porque essa geração, com toda a sua complexidade, possui características extremamente competitivas, devido à forma como foi educada por seus pais e ao fato de ter crescido utilizando todo o aparato tecnológico. 
Em um ambiente cada vez mais competitivo e com as dificuldades do gestor em manter o colaborador satisfeito no ambiente de trabalho, bem como dirimir os conflitos, é oportuno compreender como o setor bancário vem administrando esse novo ambiente, principalmente com o crescimento da mão de obra dos profissionais caracterizados como Geração Y. O bom uso das características profissionais dos jovens da Geração $Y$ tem sido um desafio para os seus gestores, pois esses jovens possuem facilidade para aprendizado e manuseio de novas tecnologias, facilidade para realização de diversas tarefas e ambição por crescimento profissional. Contraposto a essas características, os jovens $\mathrm{Y}$ têm dificuldade em permanecer na mesma função por um longo período de tempo, elevada autoestima e dificuldades na identificação hierárquica dos gestores.

O problema está em: como realizar uma gestão que propicie um ambiente de trabalho saudável e produtivo, respeitando as limitações da Geração Y e as limitações do HSBC Bank Brasil S.A? Investigar como os gestores, no Banco HSBC Bank Brasil S.A, desenvolvem habilidades e ferramentas para gerenciar as expectativas dos profissionais que pertencem à Geração Y.

a) Identificar quem são os jovens da Geração $Y$ que atuam no HSBC Bank Brasil S.A.;

b) Demonstrar como os gestores caracterizam e administram os jovens da Geração $Y$, colaboradores do HSBC Bank Brasil S.A.;

c) Compreender como os gestores direcionam ou alteram suas ações com relação aos integrantes da Geração Y para mantê-los no quadro de colaboradores do HSBC Bank Brasil S.A.

Uma geração que está tomando conta do mercado com seu jeito arrojado e peculiar de ver as coisas é a Geração Y. Para que se possa utilizar todo o potencial dos jovens $Y$, que compõem o capital humano dos bancos, é pertinente que seja realizada uma análise sobre como os gestores das instituições financeiras fomentam o crescimento profissional, quais ferramentas utilizam na gestão e como conseguem gerenciar a ânsia que os jovens $\mathrm{Y}$ têm por uma promoção rápida e, consequentemente, gerenciar a frustração de não conseguir uma promoção no tempo que foi almejado por eles. Para que os bancos tenham uma continuidade em seus negócios de forma sustentável, é relevante a identificação dos estímulos profissionais da Geração Y, pois são esses jovens que atuarão no mercado nas próximas décadas, sendo importante saber o que eles esperam da instituição financeira em que trabalham. As características da Geração Y são explicadas por Lombardia (2008) como uma geração que engloba os jovens que nasceram entre os anos 80 e 90 . Alguns pontos sobressaem na criação desses jovens, como a elevada preocupação da sociedade com sua segurança e o fato de ainda quando crianças a Geração Y já possui uma segurança em si mesma.

Essa geração traz, em si, toda uma estrutura familiar, toda uma proteção e preocupação que seus pais têm com sua segurança. Para Lipkin e Perrymore (2010), os pais da Geração Y desenvolveram um relacionamento saudável, dando toda estrutura para que eles pudessem crescer e se expressar de forma livre. Esse bom relacionamento que os pais da Geração $Y$ tiveram com seus filhos é definido por Lancaster e Stillman (2011) por meio de sete tendências que, juntas, formam o fator M. São elas: educação no lar, direitos garantidos, significado, grandes expectativas, necessidade de dinamismo, rede social e colaboração. O entendimento dessas sete tendências facilita a compreensão do perfil da Geração Y. A educação no lar demonstra que o filho $\mathrm{Y}$ é o orgulho de seus pais. Sendo assim, quando esse filho cresce e se insere no meio escolar e profissional, os pais tendem a acompanhá-lo.

A garantia dos direitos faz parte das sete tendências citadas por Lancaster e Stillman (2011), pois essa geração recebeu de seus pais uma intensa valorização da autoestima, além de muitos elogios. É uma geração que oferece muito às empresas; no entanto, deseja receber na mesma proporção. Para essa geração, o que importa é o sentido das coisas. O emprego, por si só, não lhes causa admiração; eles precisam se sentir participantes da missão maior da empresa, como também querem colaborar com a sociedade. $\mathrm{Na}$ 
tendência de grandes expectativas, a Geração Y busca o emprego que realmente tem a ver com ela. Quando o jovem Y não se sente confortável na empresa onde trabalha, não hesita em buscar um novo emprego. Esse modo de levar a vida gera surpresas nos tradicionalistas -Baby Boomers e Geração X-, levando ao conflito dentro das organizações, sendo o setor bancário também um dos atingidos.

A Geração Y nasceu em um tempo de constante evolução tecnológica, tendo um perfil muito dinâmico. Devido à grande velocidade com que a Geração Y aprendeu a se comunicar e a debater assuntos variados, está ocorrendo a reinvenção da comunicação, o que preocupa à geração que a antecede, ou seja, se esse novo processo ocorrerá de forma responsável. O tema é relevante e atual, porque se tem percebido, no mundo do trabalho, uma constante preocupação em buscar soluções plausíveis para os conflitos que estão ocorrendo no ambiente empresarial. Devido ao elevado número de publicações bibliográficas e pesquisas realizadasnosúltimosanos, no sentidodeentender quais fatores motivam o crescimento profissional dos jovens da Geração Y, considera-se pertinente que ocorra um estudo do comportamento da Geração Y no setor bancário e, por conseguinte, a identificação da gestão que ocorre pelos gestores no setor bancário. Nos dias atuais, entre os grupos que compõem a sociedade, estão, conforme já se mencionou: a Geração Baby Boomers, a Geração $X$ e a Geração Y. Cada uma dessas gerações tem o seu perfil definido por um estudo chamado de análise de coorte, a qual investiga "[...] as mudanças em padrões de comportamento ou atitudes de grupos chamados coortes". (BLACKWELL; MINIARD; ENGEL, 2005, p. 339).

\section{A Geração Y}

O formato da sociedade nos anos de 1980 foi o cenário onde surgiu a Geração Y. Nesse período, a televisão, que tanto influenciou as gerações anteriores, deu lugar à internet. A agilidade na absorção das informações é um reflexo do momento em que as crianças $\mathrm{Y}$ nasceram e se desenvolveram. Outros fatores também contribuíram para a formação do perfil dessa geração, como as mudanças de tecnologia e as variedades na comunicação, além da educação diferenciada que receberam de seus pais. Algumas das influências citadas são descritas por Lombardia (2008) os jovens Y nasceram entre os anos 80 e 90, são crianças alegres, desejados e protegidos pela sociedade, é a geração dos Power Rangers que dominam a internet e as tecnologias.

Em meio a tantas mudanças no tecido social e à superproteção recebida de seus pais, essa geração, que está em ascensão no mercado e, a cada dia, gera polêmicas pela sua forma de ver a vida, tem um retardo na independência financeira e na constituição da família pelas razões explicadas por Oliveira (2012) a Geração $X$ amenizou a exposição dos jovens $Y$ ao convívio social, de forma que os pedidos dos $\mathrm{Y}$ eram sempre atendidos por seus pais integrantes da Geração X. Um exemplo de tal situação é a disponibilidade de um jovem $\mathrm{Y}$ por incentivo de seus pais ingressar no mercado de trabalho somente depois da formação universitária, esse modo de tratamento que os $\mathrm{Y}$ receberam acarretou um retardo na independência financeira e consequentemente um atraso na criação da família.

Os jovens da Geração Y receberam uma elevada proteção de seus pais, os quais, em virtude dessa proteção, se tornaram seus melhores amigos, tanto que esses jovens permitem, até mesmo, que seus pais negociem situações nos ambientes profissionais. Lancaster e Stillman (2011) exemplificam o pensamento dos jovens $Y$ como sendo uma consequência da proteção familiar, esses jovens sentem-se confortáveis com seus pais negociando seus salários e benefícios pois acreditam que seus conselhos são confiáveis, no entanto esse conforto dos jovens $\mathrm{Y}$ não é bem visto por outras gerações. Essa confiabilidade que os jovens $Y$ têm em seus pais é descrita por Ashley Strub, 24 anos, em Lancaster e Stillman (2011, p. 33):

Considero meus pais meus melhores amigos. E é a eles que recorro quando preciso de um conselho. Quando estava tentando escolher os benefícios do meu emprego, o que eu deveria deixar de lado, quanto colocar no meu plano de compra de ações... Para todas essas questões, consultei-os. Nosso departamento de 
RH tem dito que, em geral, os jovens precisam ligar para os pais antes de decidir se aceitam uma oferta de emprego. É ótimo termos essa intimidade, porque eles já passaram por isso e cometeram enganos, assim podemos aprender com eles.

Comabagagemfamiliardescritaanteriormente, os jovens $\mathrm{Y}$ chegam ao mercado de trabalho com uma elevada autoestima, o que lhes atribui características profissionais particulares. No que diz respeito às características que formam o perfil profissional da Geração $Y$, alguns pontos ocupam lugar de destaque, quando esses jovens são analisados pelo mercado. Muitas dessas características são heranças do período em que nasceram e da forma como seus pais conduziram sua educação. $\mathrm{O}$ bom entendimento do momento em que nasceram os profissionais da Geração Y ajuda a compreendê-los. Para Gomes (2013), pelo fato de o nascimento dos jovens dessa geração ter ocorrido no momento em que a internet se tornou popular, os mesmos têm facilidade de se adaptarem à evolução da tecnologia, capacidade de realizar diversas tarefas ao mesmo tempo, pouca flexibilidade para uma possível estagnação na carreira, ânsia por um rápido sucesso financeiro e inclinação para causas sociais.

Em resumo, essas características são particulares dessa geração, pois os eventos ocorridos no momento de seu nascimento e no decorrer de seu crescimento fizeram com que os jovens $\mathrm{Y}$ tivessem esse tipo de comportamento. Para Lipkin e Perrymore (2010) os integrantes desta polemica geração tem um perfil dinâmico, com elevada autoestima, são criativos e abertos ao convívio social. Eles não têm dificuldades de questionar seus gestores por que eles possuem a mesma idade de seus pais. As gerações que questionam os jovens $\mathrm{Y}$ também foram revolucionárias em sua época, a diferença é que eles o fizeram em outras áreas e a Geração $\mathrm{Y}$ esta atuando no âmbito profissional. Muitas das características que os jovens $Y$ possuem, formam uma espécie de barreira para se protegerem do mercado de trabalho. Para Oliveira (2012), o mercado está pouco tolerante ao fracasso, sendo que ser bem-sucedido nas carreiras corporativas possui um grande significado, além de que fracasso é sinônimo de derrota. Por essa razão, os pais da Geração $Y$ se preocuparam tanto com a autoestima de seus filhos, mesmo nos períodos da educação escolar.

No que diz respeito à autoestima, na visão de Lipkin e Perrymore (2010), no momento da infância, os pais incentivaram, de forma expressiva, a autoestima de seus filhos, sendo comuns frases como: "Você pode ser o que quiser e Você é um vencedor". Tais iniciativas foram desenvolvidas por uma preocupação com a saúde e com o sucesso no ambiente profissional e pessoal. No entanto, inibiu o desenvolvimento da humildade e a adaptabilidade em aprender com os erros. Por esses motivos, a Geração Y tem, em seu perfil, características, como criatividade e boa produtividade no trabalho. Tais características são encontradas em profissionais com uma autoestima elevada. Para os gestores dos jovens Y, o desafio está em gerenciar uma geração com tamanha vontade de se desenvolver profissionalmente e com pouca paciência para esperar uma promoção que possa levar mais tempo do que eles imaginam para acontecer.

\section{A Geração y no setor bancário}

Para essa geração tecnológica, os bancos desenvolveram métodos de retenção do capital humano e métodos de prospecção de potenciais clientes da chamada Geração Y. Segundo dados do Sindicato dos Bancários de Jundiaí e Região (2010, p.1), “o segmento financeiro é o maior investidor brasileiro em tecnologia da informação, sendo responsável anualmente por $18 \%$ de todas as aquisições de tecnologia". Os bancos acreditam no potencial dos jovens $\mathrm{Y}$, tanto na área de tecnologias, quanto na de investimentos e produtividade profissional. No evento apreciado pelo Sindicato dos Bancários de Jundiaí e Região (2010), a Federação Brasileira de Bancos (FEBRABAN) promoveu, em 2010, uma feira, no Congresso e Exposição de Tecnologia da Informação das Instituições Financeiras (CIAB), onde foram apresentados aplicativos para investimentos, utilizando o Iphone, extratos interativos com áudio e vídeo, inovações que têm o intuito de interagir com o jovem público da Geração Y. 
Os investimentos para interagir com os jovens Y são elevados. No entanto, conforme pesquisa realizada pela Bridge Recearch, que analisou a relação que os jovens $\mathrm{Y}$ brasileiros têm com os bancos, essa geração mantém certo receio em relação a essas empresas (TRINDADE, 2011). Ainda segundo o autor, o estudo foi realizado com 670 jovens $Y$ (entre 20 e 29 anos), e os resultados apontaram que a Geração Y está distante e desconfiada com as práticas das organizações financeiras e que esses jovens alegam que não há interesse dos bancos em fidelizá-los, existindo relevante burocracia para abrir uma conta. Além disso, os jovens que são correntistas trabalham com o banco por incentivo dos pais, e não por motivação própria. No âmbito profissional, os jovens $\mathrm{Y}$ possuem características que os bancos podem gerenciar de forma eficaz, como relata Porto (2011, p. 20):

- Abertos a novas e constantes experiências,

- Interconectados,

- Focados no seu autodesenvolvimento profissional,

- Lealdade de natureza 'transacional' - maior rotatividade,

- Constroem suas carreiras tendo como pressuposto a mobilidade (Inter e Intraempresas) - busca de incremento constante da empregabilidade,

- Ocupam funções executivas mais cedo,

- Estabelecem vínculos com pessoas (colegas e liderança imediatas) e com valores organizacionais,

- Movidos pela busca do 'sentido' (paixão pelo que faz): ética do prazer>ética do dever,

- Chegam ao mercado de trabalho com maiores capacidades, habilidades e conhecimentos teóricos,

- Preocupados com a responsabilidade ambiental e social.

Preocupadocom odesenvolvimento profissional da Geração Y, o Banco HSBC criou o grupo de afinidade "Geração Y". Segundo It Careers (2011), o grupoé formado por colaboradores das diversas áreas da instituição financeira e tem o objetivo de fortalecer a instituição no mercado e tornar o banco mais atrativo para os novos talentos que aspiram a uma carreira no ambiente financeiro, além de procurar entender o consumidor de um futuro próximo, tendo a relevância que essa geração ultrapassa 16 milhões de integrantes.

\section{Caracterização da empresa}

Fundado em Hong Kong, para servir comerciantes de chá da região, e, atualmente, com a matriz em Londres, Inglaterra, o HSBC atua na área financeira desde 1865 . No mundo, o Grupo HSBC é conhecido como HSBC Holdings plc e possui cerca de 6.900 escritórios em mais de 80 países e territórios da Europa, ÁsiaPacífico, Américas, Oriente Médio e África, aproximadamente, 27.500 colaboradores e mais de60 milhões de clientes(HSCC, 2013). Com ações cotadas nas principais bolsas internacionais, como Londres, Hong Kong, Nova Iorque, Paris e Bermuda, tem um quadro de acionistas superior a 221.000, distribuídos em de 135 países e territórios. (HSBC, 2013). No Brasil, iniciou suas atividades no ano de 1997, quando incorporou o Banco Bamerindus S.A. desse então segundo HSBC (2013) a rede de agencias que contempla 866 agencias e 399 postos de atendimento bancário (PAB) encontrasse presente em mais de 545 municípios no território nacional, compõe também a estrutura operacional do Banco HSBC 1030 postos de atendimento eletrônico, 2505 ambientes de autoatendimento, mais de 5200 caixas. Os clientes contam com uma rede compartilhada de caixas automáticos que ultrapassa 38 mil caixas e os cartões de debito e credito são aceitos em amis de 61 milhões de estabelecimentos no Brasil e no exterior.

Sua área social é conhecida como HSBC Solidariedade (IHS), que fomenta projetos socioambientais no cenário brasileiro. O IHS foi acolhido como associado do Departamento de Informações Públicas da Organização das Nações Unidas (ONU), sendo a primeira Organização NãoGovernamental (ONG) corporativa do mundo a se associar à ONU (HSBC, 2013). O reconhecimento ocorreu pela constante contribuição do IHS para o cenário brasileiro. Atualmente, o Brasil é a quarta maior fonte de contribuição para os resultados da HSBC Holdings plc, depois de Hong Kong, Reino Unido e China. O resultado é expressivo, pois representa mais da metade do 
lucro da América Latina e deve-se ao crescimento do crédito no segmento de pessoa jurídica e nas relações Brasil-China (HSBC, 2013). A Regional Florianópolis está situada no Estado de Santa Catarina e, junto com o Estado do Rio Grande do Sul, compõe a Rede Sul, que, por sua vez, faz parte das demais redes que compõem o Banco HSBC no Brasil. Essa regional está subdividida em microrregiões, que são compostas de quatro ou cinco cidades.

\section{Análise da situação atual da empresa e discussões}

$\mathrm{O}$ resultado obtido com $\mathrm{O}$ questionário aplicado para 20 colaboradores do HSBC Bank Brasil S.A., da microrregião Vale Europeu, que engloba as cidades catarinenses de Brusque, Guabiruba, Rio do Sul, Otacílio Costa e Presidente Getúlio, visa identificar os jovens da Geração Y que atuam no HSBC Bank Brasil S.A. Assim, podemos observar a partir de agora as características dos Y que atuam no HSBC Bank Brasil S.A.

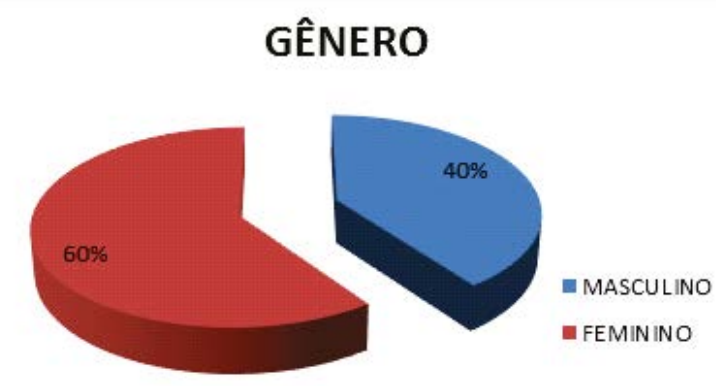

Gráfico 1. Gênero da Geração Y

Fonte: Elaborado pelo autor (2013).

Conforme apresenta o Gráfico 1, dos colaboradores da Geração $Y$ participantes desta pesquisa, $60 \%$ são do sexo feminino e $40 \%$ do gênero masculino, havendo, portanto, predominância do gênero feminino.

\section{IDADE}

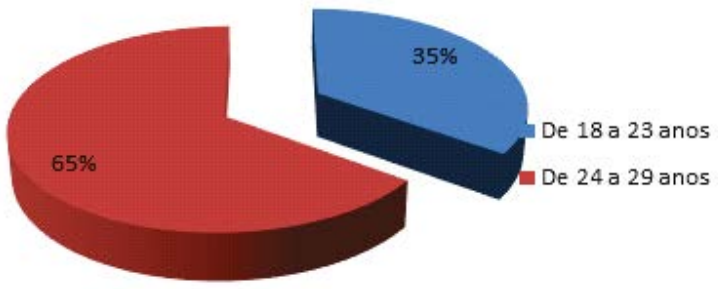

Gráfico 2. Idade da Geração Y

Fonte: Elaborado pelo autor (2013).

O Gráfico 2 aponta, em relação à idade dos colaboradores, que $65 \%$ possuem idade entre 24 e 29 anos e $35 \%$, entre 18 e 23 anos. A idade apresentada vai ao encontro do estudo de Lombardia (2008), segundo o qual a idade característica dos jovens da Geração Y abrange os nascidos das décadas de 1980 e 1990.

\section{GRAU DE ESCOLARIDADE}
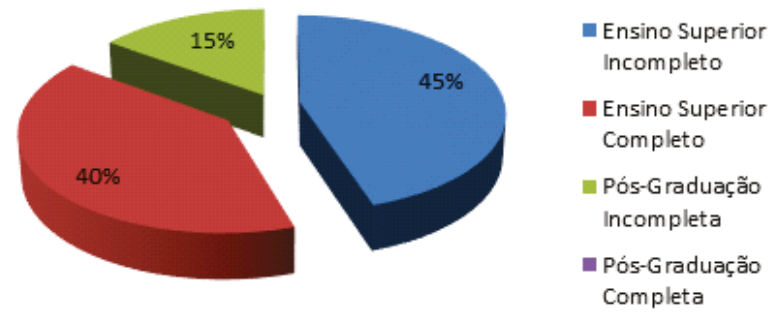

Gráfico 3. Grau de escolaridade

Fonte: Elaborado pelo autor (2013).

Quanto ao nível de instrução dos colaboradores, o Gráfico3 expõe que $45 \%$ possuem curso superior incompleto; $40 \%$, curso superior completo; $15 \%$, pós-graduação incompleta; e nenhum possui pós-graduação completa. 


\section{TEMPO DE ATUAÇÃO NA EMPRESA}

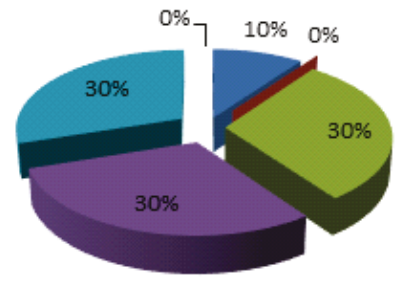

De 1 a 6 Meses

De 7 a 11 Meses

- De 1 a 2 Anos

- De 3 a 5 Anos

- De 6 a 9 Anos

Acima de 10 Anos

Gráfico 4. Tempo de atuação na empresa

Fonte: Elaborado pelo autor (2013).

No que diz respeito ao tempo de atuação na empresa, conforme apresenta o Gráfico 4, dos participantes deste estudo, 50\% responderam que trabalham de 3 a 5 anos na empresa; 30\%, que trabalham de 6 a 9 anos; 30\%, de 1 a 2 anos; $10 \%$, de 1 a 6 meses, não havendo colaborador da Geração Y que trabalhe há mais de 10 anos na empresa.

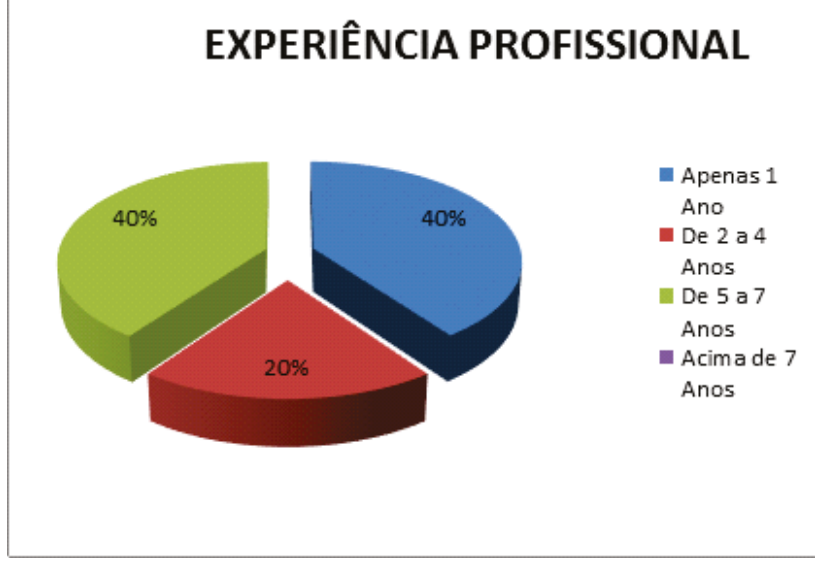

Gráfico 5. Experiência profissional

Fonte. Elaborado pelo autor (2013).

Em consonância com o Gráfico 5, sobre a experiência profissional, $40 \%$ dos jovens $\mathrm{Y}$ participantes da pesquisa apontaram que $o$ número de empresas nas quais trabalharam foi de 5 a 6 e $40 \%$, que foi de uma empresa. Os demais, num total de $20 \%$, declararam que o número de empresa nas quais atuaram foi de 2 a 4, não havendo respondente que tenha trabalhado em mais de 7 empresas.

\section{INTERAÇÃO COM A TECNOLOGIA}

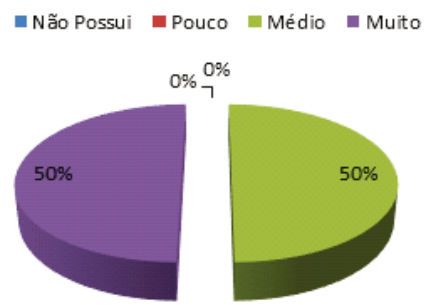

Gráfico 6. Interação com a tecnologia

Fonte: Elaborado pelo autor (2013).

No que tange à interação com a tecnologia, o Gráfico 6 expõe que $50 \%$ dos avaliados possuem média interação com a tecnologia e $50 \%$, muita interação com a tecnologia.

\section{MOTIVAÇÃO PARA DESAFIOS}

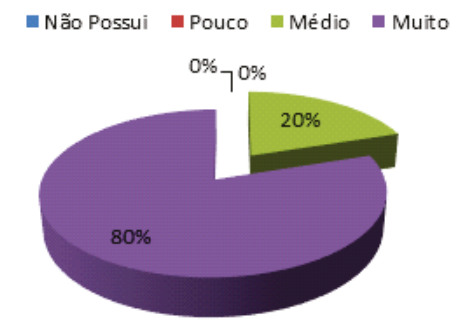

Gráfico 7. Motivação para desafios

Fonte: Elaborado pelo autor (2013).

De acordo com o Gráfico 7, os resultados obtidos para a questão referente à motivação para desafios foram: $80 \%$ dos avaliados possuem muita motivação para desafios e $20 \%$, uma média motivação.

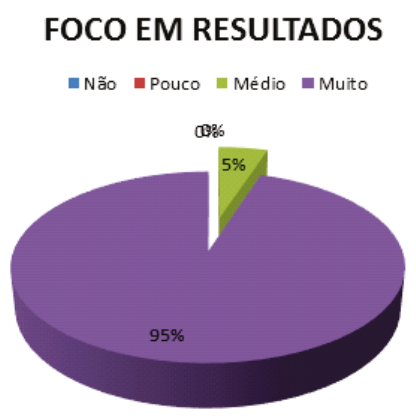

Gráfico 8. Foco em resultados

Fonte: Elaborado pelo autor (2013). 
Em consonância com o Gráfico 8, tem-se que 95\% dos colaboradores possuem muito foco nos resultados, enquanto $5 \%$ possuem médio foco.

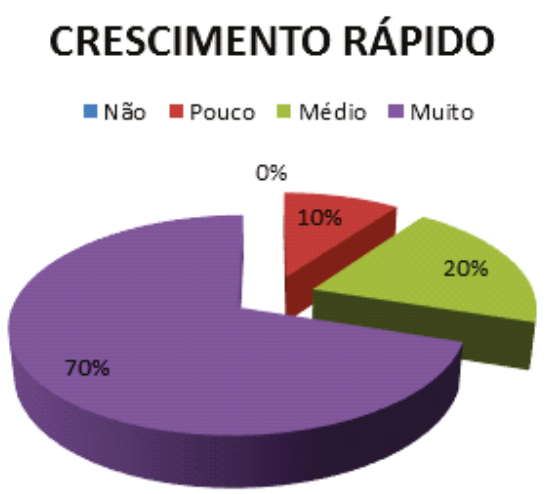

Gráfico 9. Crescimento rápido

Fonte: Elaborado pelo autor (2013).

Em referência a um crescimento profissional rápido, o Gráfico 9 permite visualizar que $70 \%$ dos colaboradores da Geração Y querem um crescimento muito rápido, $20 \%$ almejam um crescimento de forma mediana e $10 \%$ procuram pouco o crescimento profissional de forma rápida.

\section{AUTONOMIA NO TRABALHO}

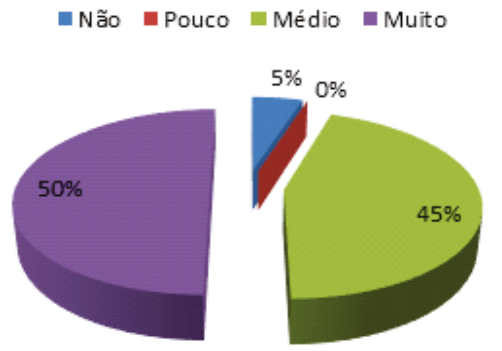

Gráfico 10. Autonomia no trabalho

Fonte: Elaborado pelo autor (2013).

Para a questão de trabalhar com autonomia, segundo mostra o Gráfico 10, 50\% dos respondentes demonstraram ter preferência por um trabalho com maior índice de autonomia, $45 \%$ responderam que preferem uma média autonomia no trabalho e 5\% não têm preferência por ter autonomia no trabalho.

\section{FORMA DE TRABALHO}

aSOZINHO EEQUIPE

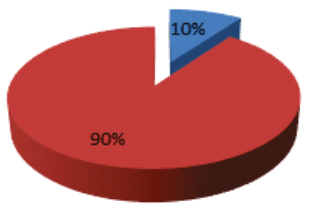

Gráfico 11. Forma de trabalho

Fonte: Elaborado pelo autor (2013).

Em relação à preferência pela forma de trabalho, conforme o Gráfico 11, os resultados foram: $90 \%$ dos entrevistados responderam que têm preferência por trabalhar em equipe, enquanto $10 \%$ demonstraram ter interesse em trabalhar sozinho.

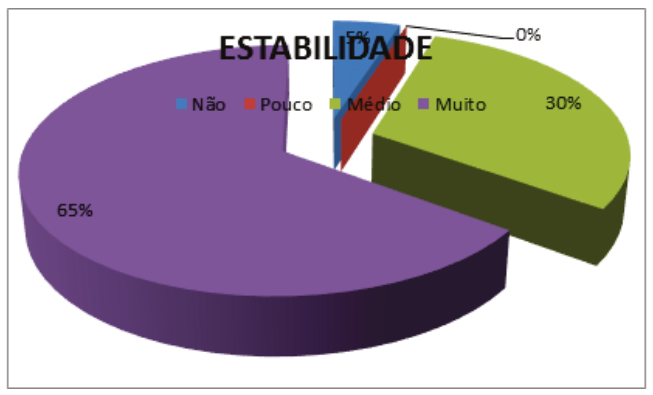

Gráfico 12. Estabilidade

Fonte: Elaborado pelo autor (2013).

O Gráfico 12 expõe que 65\% dos entrevistados têm preferência por muita estabilidade no trabalho; $30 \%$ possuem um médio interesse por estabilidade; e $10 \%$ não têm interesse por estabilidade no trabalho.

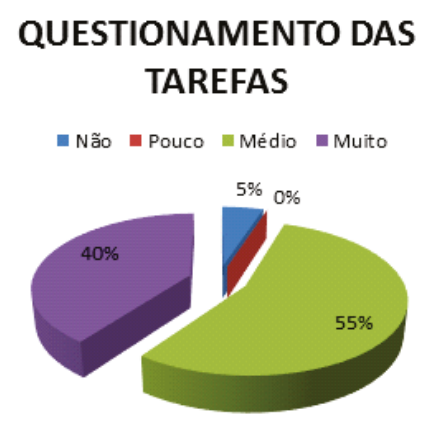

Gráfico 13. Questionamento das tarefas Fonte: Elaborado pelo autor (2013). 
No Gráfico 13, têm-se os seguintes resultados: 55 dos respondentes questionam de forma mediana as tarefas, $40 \%$ questionam muito as tarefas e $55 \%$ não questionam as tarefas que lhes são dispensadas.

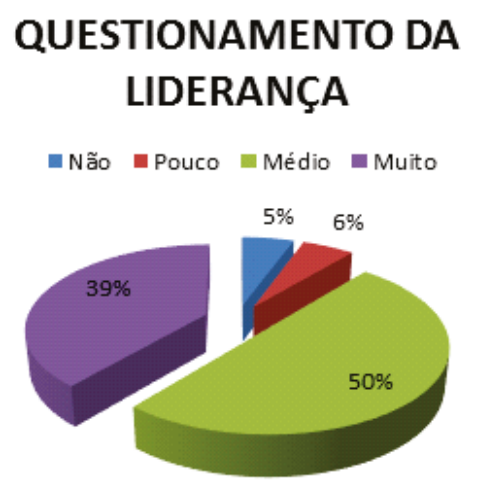

Gráfico 14. Questionamento da chefia

Fonte: Elaborado pelo autor (2013).

No que diz respeito ao questionamento da chefia, o Gráfico 14 permite observar o seguinte: $50 \%$ responderam que questionam de forma mediana os seus superiores imediatos; $39 \%$, que questionam muito seus superiores imediatos; $6 \%$, que questionam pouco os superiores; e $5 \%$ que não questionam seus superiores imediatos.

\section{EQUILIBRIO PROFISSIONAL E PESSOAL}

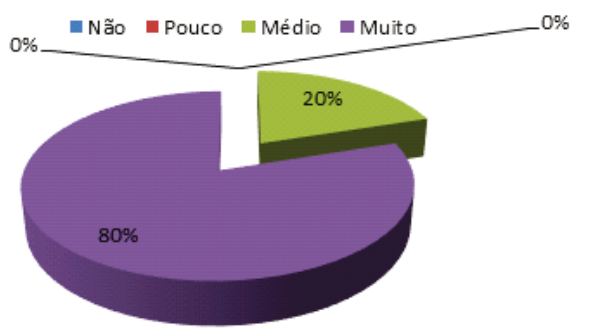

Gráfico 15. Equilíbrio profissional e pessoal Fonte: Elaborado pelo autor (2013).

Por meio do Gráfico 15, pode-se perceber que $80 \%$ dos respondentes buscam muito o equilíbrio entre a vida profissional e pessoal e $20 \%$ buscam de forma mediana esse equilíbrio.

\section{FEEDBACK NAS TAREFAS}

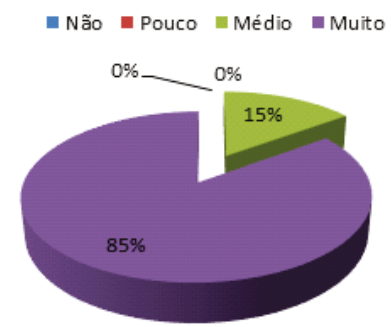

Gráfico 16. Feedback das tarefas

Fonte: Elaborado pelo autor (2013).

Conforme se tem no Gráfico 16, dos respondentes ao questionário, $85 \%$ querem muito receber feedback das tarefas realizadas e $15 \%$ querem ter um mediano feedback das tarefas realizadas.

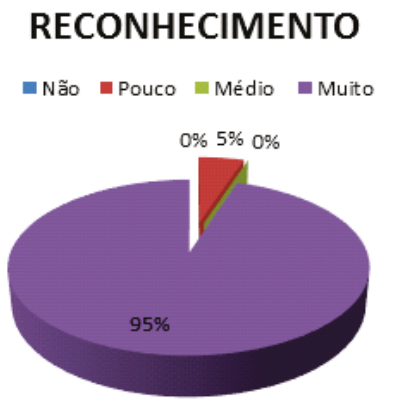

Gráfico 17. Reconhecimento

Fonte: Elaborado pelo autor (2013).

No Gráfico 17, têm-se os resultados obtidos no que diz respeito ao reconhecimento no trabalho: $95 \%$ responderam que querem muito ser reconhecidos pelo trabalho que realizam e 5\% têm preferência por um mediano reconhecimento pelo trabalho que realizam. A análise dos resultados obtidos com o questionário aponta, em síntese, que, entre os colaboradores da Geração Y que atuam no HSBC Bank Brasil S.A: predomina o sexo feminino; a idade varia entre 18 e 29 anos; a maioria concluiu ou está cursando o curso superior; o número de empresas em que atuaram varia de 6 meses a 9 anos; o número de empresas em esses jovens atuaram varia de 2 a 6 anos; possuem interação com a tecnologia; possuem interesse em aprender e se 
desenvolver; conseguem desempenhar mais de uma tarefa simultaneamente; estão motivados para desafios; possuem foco nos resultados; querem crescimento; tem preferência por um trabalho com maior índice de autonomia; preferem trabalhar em equipe; tem preferência por estabilidade no emprego; questionam as tarefas e seus superiores diretos; buscam equilíbrio entre a vida profissional e pessoal; querem receber feedback das tarefas realizadas; e não possuem dificuldades de relacionamento com os Baby Boomers e com a Geração X.

\section{Considerações Finais}

O mundo corporativo vem se adaptando às mudanças que ocorrem no mercado. De acordo com a necessidade que se apresenta, são desenvolvidas ferramentas, processos de gestão, teorias do comportamento humano, competências gerenciais ou simplesmente mudanças que surtem consideráveis efeitos na relação entre os objetivos da organização, sendo essa sua missão e visão, e os objetivos dos colaboradores, sendo esses representados pela expectativa de sucesso no âmbito pessoal e profissional. A relação entre objetivos corporativos e objetivos dos colaboradores tornase complexa à medida que as características dos colaboradores passam por metamorfoses, ou seja, quando foi desenvolvida a teoria científica de Taylor, a preocupação das empresas era com a produtividade e com o lucro. Não havia preocupação com os colaboradores ou com o gerenciamento das necessidades básicas do capital humano no ambiente laboral. Nesse período, a força produtiva das organizações trabalhava apenas para sobreviver, não havendo reivindicações ou preocupação com o que os colaboradores pensavam.

Após a teoria científica, surgiram outras teorias que aperfeiçoaram a temática científica. Nesse contexto de surgimento de teorias que se complementam, surgiram, também, gerações com características diferentes. Foi neste sentido que se desenvolveu o presente trabalho, que teve, como objetivo geral, investigar como os gestores, no Banco HSBC Bank Brasil S.A., desenvolvem habilidades e ferramentas para gerenciar as expectativas dos profissionais que pertencem à Geração $\mathrm{Y}$ e, como objetivos específicos: a) identificar quem são os jovens da Geração Y que atuam no HSBC Bank Brasil S.A.; b) demonstrar como os gestores caracterizam e administram os jovens da Geração Y, colaboradores do HSBC Bank Brasil S.A.; compreender como os gestores direcionam ou alteram suas ações com relação aos integrantes da Geração Y para mantê-los no quadro de colaboradores do HSBC Bank Brasil S.A. Os resultados obtidos com este estudo possibilitaram constatar que, em muitos aspectos, os jovens $\mathrm{Y}$ estão dispostos a se desenvolver na organização e buscam até mesmo estabilidade. Esses jovens priorizam, no entanto, determinadas necessidades, que, se forem sanadas pela organização, levarão a uma evolução na relação entre líderes e liderados e, consequentemente, a uma maior produtividade da empresa. Com base nos estudos realizados, recomendou-se ao HSBC Bank Brasil S.A, que a organização pode valer-se de oportunidades internas para atender a essa necessidade dos jovens Y e que a divulgação dessas oportunidades podem ser feitas por intermédio do superior imediato, correio eletrônico, intranet corporativa e, até mesmo, pelo site da organização.

\section{Referências}

Blackwell, Roger D.; Miniard, Paul W.; Engel, James F. Comportamento do consumidor. São Paulo: Cengage Learning, 2005.

Gomes, Adriana. Os profissionais da Geração Y. Disponível em: <http://www.vidaecarreira. com.br/os-profissionais-da-geracao-y/>. Acessado em 20 maio 2013.

Lancaster, Lyanne C.; Stillman, David. O y da questão: como a geração Y está transformando o mercado de trabalho. São Paulo: Saraiva, 2011.

Lipkin, Nicole; Perrymore, April. A Geração $Y$ no Mercado de Trabalho: Como lidar com a força de trabalho que influenciará definitivamente a cultura da sua empresa. Rio de Janeiro: Elsevier, 2010. 
Lombardia, Pilar Garcia. Quem é a Geração Y. Revista HSM Management, 70, Set-Out 2008. Disponível em: <www.hsm.com.br/revista/ quem-e-geracao-y $>$. Acessado em 18 mar. 2013.

Oliveira, Sidney; Jovens para sempre: Como entender os conflitos de gerações. São Paulo: Integrare Editora, 2012.

Porto, Claudio. Retrato do mercado bancário para $R H$. Oportunidades $x$ AmeaçasUma visão Panorâmica. Disponível e m: $<$ h t t p : / w w w f ebraban.org. br/7Rof7SWg6qmyvwJcFwF7I0aSDf9jyV/ sitefebraban/Claudio $\% 20$ Porto $\% 20-\% 20$ AUTORIZADA.pdf $>$. Acessado em 14 jun. 2013.
Serrano, Daniel Portillo. Geração Baby Boomer. Disponível em: <http://www. portaldomarketing.com.br/Artigos/ Geracao_Baby_Boomer.htm>. Acessado em 20 maio 2013.

Sindicato dos bancários de jundiaí. Setor bancário investe em novidades para a Geração Y. Disponível em: <http://www. bancariosjundiai.com.br/noticias_detalhes. php=602>. Acessado em 21 maio 2013.

Trindade, Renato. Foco em Gerações. Disponível em: <http://www.focoemgeracoes.com.br/ index.php/2011/12/12/pesquisa-identificapercepcao-que-a-geracao-y-tem-sobre-osbancos/ > . Acessado em 21 maio 2013. 